MIDAS

Museus e estudos interdisciplinares

$10 \mid 2019$

Varia

\title{
Colecciones etnográficas y sus potencialidades educativas: una experiencia de activación patrimonial
}

Ethnographic collections and their educational potential: an experience of heritage activation

María Marta Reca, Ana Inés Canzani y María Cecilia Luz Domínguez

OpenEdition

Journals

Edición electrónica

URL: http://journals.openedition.org/midas/1756

DOI: $10.4000 /$ midas. 1756

ISSN: 2182-9543

Editor.

Alice Semedo, Paulo Simões Rodrigues, Pedro Casaleiro, Raquel Henriques da Silva, Ana Carvalho

Referencia electrónica

María Marta Reca, Ana Inés Canzani y María Cecilia Luz Domínguez « Colecciones etnográficas y sus potencialidades educativas: una experiencia de activación patrimonial », MIDAS [En línea], 10 | 2019, Puesto en línea el 31 mayo 2019, consultado el 16 junio 2019. URL : http://journals.openedition.org/ midas/1756 ; DOI : 10.4000/midas.1756

Este documento fue generado automáticamente el 16 junio 2019

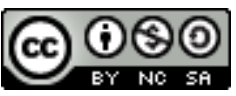

Midas is licensed under a Creative Commons Attribution-NonCommercial-ShareAlike 3.0 International License 


\title{
Colecciones etnográficas y sus potencialidades educativas: una experiencia de activación patrimonial
}

\author{
Ethnographic collections and their educational potential: an experience of \\ heritage activation
}

María Marta Reca, Ana Inés Canzani y María Cecilia Luz Domínguez

\section{NOTA DEL EDITOR}

Artigo recebido a 27.06.2018

Aprovado para publicação a 20.12.2018

\section{Introducción}

1 En las últimas décadas se viene trabajando en un entramado conceptual paradigmático que impacta en el accionar político institucional y educativo de los museos, a saber: la apertura hacia la pluralidad de interpretaciones y usos sociales en torno al patrimonio. Este giro conceptual es concebido por algunos autores como el pasaje del discurso monológico al dialógico, distinguido a partir del estatus concedido al "otro" en la representación discursiva (Gutiérrez Estévez 1998).

En sentido amplio, se entiende por discurso al sistema de representación inter-semiótico y comunicacional que adopta vigencia en un momento dado. Lo que caracteriza al modelo monológico es la cosificación del "otro", mientras que en el modelo dialógico, el "otro" ostenta el estatus de interlocutor. Esta distinción epistémica desplaza la producción de sentido y su representación hacia la relación entre el sujeto y el objeto, generando un 
espacio de interacción. Veremos cómo, en el ámbito de un museo, la práctica curatorial tradicional se encuentra, entonces, cuestionada o interpelada por estos modelos dialógicos, los cuales desembocan en políticas participativas.

3 En esta apertura hacia la diversidad de interpretaciones y las múltiples facetas comunicativas de un objeto, subyace el concepto antropológico de diversidad, el cual transita en las ciencias sociales contrarrestando las perspectivas esencialistas y reduccionistas de la identidad (Dietz y Mateos Cortés 2010; Hernández Hernández 2011).

En relación al patrimonio cultural, la UNESCO incluye al patrimonio cultural inmaterial dentro de la Convención para la Salvaguardia del Patrimonio Cultural Inmaterial (2003) y su proclamación antropológico-pedagógica. Dicha Convención ha puesto en valor la diversidad como un recurso y como un derecho, definiendo el patrimonio cultural inmaterial por:

[...] los usos, representaciones, expresiones, conocimientos y técnicas - junto con los instrumentos, objetos, artefactos y espacios culturales que les son inherentes que las comunidades, los grupos y en algunos casos los individuos reconozcan como parte integrante de su patrimonio cultural. Este patrimonio cultural inmaterial, que se transmite de generación en generación, es recreado constantemente por las comunidades y grupos en función de su entorno, su interacción con la naturaleza y su historia, infundiéndoles un sentimiento de identidad y continuidad y contribuyendo así a promover el respeto de la diversidad cultural y la creatividad humana. (UNESCO 2003, artículo 2)

5 En este contexto se asume, entonces, una definición dinámica de patrimonio cultural, concebido como el producto de una construcción social situada en un contexto sociopolítico particular. Así, los patrimonios son repertorios activados socialmente por versiones ideológicas de la identidad, a partir de diversos referentes tales como monumentos catalogados, espacios naturales protegidos, museos o lugares conmemorativos, entre otros (Prats 2005).

Aquí la identidad, del tipo que sea, es también una construcción social y un hecho dinámico, aunque con un razonable nivel de fijación y perpetuación, y que toda formulación de la identidad es únicamente una versión de esa identidad, un contenido otorgado a determinada etiqueta. Por tanto, pueden coexistir, y de hecho coexisten normalmente, distintas versiones de una identidad [...]. El patrimonio, o mejor dicho, las diversas activaciones de determinados referentes patrimoniales, son representaciones simbólicas de estas versiones de la identidad. (Prats 2005, 31)

Particularmente los museos de antropología o aquellos museos que conservan colecciones antropológicas en su acervo como el Museo de La Plata (Buenos Aires, Argentina), fueron y son motivo de análisis crítico de la mano de las perspectivas hermenéuticas y constructivistas en el análisis de la cultura, legitimado por la evidente vinculación entre el patrimonio, memoria e identidad (García Canclini 1978; Clifford 1991; Navarro Rojas 2011). En tal sentido, el viejo paradigma de la etnografía realista se flexibiliza ante la conciencia de la diversidad de representaciones que hacen del mundo un lugar inteligible.

7 En este nuevo contexto teórico, de corte crítico, los museos comienzan a desplegar acciones tendientes a la incorporación activa de nuevos actores sociales, para analizar y construir políticas institucionales sobre la base del diálogo y la interacción, incluyendo diversas modalidades de activación patrimonial que atraviesan la mayoría de sus funciones tradicionales, como por ejemplo los espacios expositivos. Desde el punto de vista semiótico- comunicacional, toda propuesta expositiva se concibe como una construcción intersemiótica que articula de forma específica e intencional el espacio, los objetos, las imágenes, los textos, entre otros recursos. A su vez, el visitante se concibe 
como un sujeto activo capaz de producir sentido a partir de un sistema de referencialidad, anclado tanto en el espacio expositivo como en el conjunto de representaciones sociales movilizadas, de forma selectiva, en la experiencia de la visita. Los museos han asumido cada vez con mayor convicción la diversidad de interpretaciones de las que puede ser motivo el patrimonio, generando así una "verdadera" experiencia de aprendizaje significativo. Este nuevo paradigma que adopta diversas denominaciones, tales como participativo, dialógico, inclusivo, entre otras, promueve procesos de contextualización del patrimonio etnográfico que buscan desplazar las viejas ideas sobre la identidad como una "perpetuidad congelada", con connotaciones esencialistas y reduccionistas, tanto de sus condiciones materiales como de sus valores. Por el contrario, el concepto de identidad desplegado en estas experiencias, no es, esencialista, sino estratégico y posicional (Hall 2003).

El concepto acepta que las identidades nunca se unifican y, en los tiempos de la modernidad tardía, están cada vez más fragmentadas y fracturadas; nunca son singulares, sino construidas de múltiples maneras a través de discursos, prácticas y posiciones diferentes, a menudo cruzados y antagónicos. Están sujetas a una historización radical, y en un constante proceso de cambio y transformación. [...] Las identidades tienen que ver con las cuestiones referidas al uso de los recursos de la historia, la lengua y la cultura en el proceso de devenir y no de ser; no "quiénes somos" o "de dónde venimos" sino en qué podríamos convertirnos, cómo nos han representado y cómo atañe ello al modo como podríamos representarnos. Las identidades, en consecuencia, se constituyen dentro de la representación y no fuera de ella. (Hall 2003,18)

El objetivo de este artículo es el de describir y reflexionar sobre un programa de visitas a la Sala de Etnografía - Espejos Culturales - del Museo de La Plata. En dicha experiencia se pone de manifiesto una práctica concreta de re-significación del patrimonio sobre la base del empoderamiento por parte de representantes de las culturas originarias que habitan en la ciudad de La Plata y alrededores.

\section{Exhibición y educación}

9 Desde su nacimiento, una de las misiones primordiales del museo moderno ha sido la educación, ejercida a través de diversos programas y estrategias, entre las que cuentan las exhibiciones. En los finales del siglo XIX, momento en que se sitúa la fundación del Museo de La Plata, las funciones de conservación e investigación se fortalecieron en detrimento de la función educativa, en virtud de la centralidad en el objeto y la actitud contemplativa de un público aún elitista. La disposición de las colecciones en las salas de exhibición se caracterizaba por la acumulación y el carácter enciclopédico de su presentación. Progresivamente y acompañando transformaciones sociales y políticas, la función educativa se fortalecerá a través de programas pedagógicos, creación de áreas específicas y otras acciones para definir a la institución museo al servicio de la sociedad. En relación a las exhibiciones, la nueva museología incorporará una perspectiva crítica de la museología tradicional en la que el visitante es concebido como un sujeto activo. Junto al proceso de democratización de la ciencia y la cultura, las perspectivas constructivistas fortalecerán estos espacios de educación no formal.

10 Los criterios que distinguen la educación formal, no formal e informal están ligados al grado de institucionalización, intenciones y objetivos, metodologías y sistematicidad de los procesos de aprendizaje (Valdés Sagüés 1999; Asensio Brouard, Pol Méndez y 
Carretero 2002; Asensio Brouard 2015). Los diferentes autores coinciden en la definición de educación formal mientras que los límites de la definición de las otras dos modalidades, son más difusos. Lo cierto es que el análisis de la educación no formal e informal ha llevado a reconocer múltiples y diversos ámbitos de aprendizaje natural en la vida de los individuos que, siendo igualmente intencionales, no responden a estructuras rígidas y a límites fijos en el tiempo (Asensio Brouard 2015; Fontal Merillas 2016). La institución museal puede ser partícipe de todas estas modalidades. Asumimos que la experiencia que pretendemos describir en este escrito, comparte la libertad conveniente al espacio de educación informal, favoreciendo la construcción conjunta, nunca definitiva, de saberes, enmarcados dentro de la definición de aprendizaje significativo, es decir, aquel contenido que es incorporado de forma no arbitraria y sustancial, en consonancia con estructuras preexistentes (Ausubel, Novak y Hanesian 1983; Díaz Barriga Arceo 2003). Las perspectivas más constructivistas del aprendizaje son trasladadas a la institución museo para comprender la visita a una exhibición como una experiencia situada en la que el visitante es concebido como un sujeto activo que pone en juego sus saberes e inquietudes y que se conecta con la exposición al menos en tres dimensiones: cognitiva, comportamental y emocional. A su vez, la exhibición se concibe como un contexto de representación, es el resultado de recortes, intenciones, objetivos e interpretaciones por parte de los curadores de los discursos etnográficos disciplinares producidos, en la mayoría de los casos, a partir de una situación de contacto. El curador (sujeto colectivo) sistematiza, categoriza y construye a su vez un discurso a partir de un conjunto de entidades (las colecciones), a las cuales les otorga su carácter representativo dentro del nuevo contexto (sintáctico, semántico y pragmático), transformándolo en objeto museable. En relación a la Sala de Etnografía - Espejos Culturales -, referente de este análisis, esta construcción se sustenta en las relaciones entre el conocimiento etnográfico y las colecciones, recuperando el contexto de recolección (Reca 2016).

11 Generalmente, los estudios de público han mostrado una gran variabilidad de posiciones y discursos ante una misma exposición, reconociendo los aspectos subjetivos puestos en juego en su interpretación.

Es siempre el visitante quien termina la exposición por la lectura que hace o por las formas en que se apropia de ella. Comprender que el visitante siempre es actor en alguna parte es ya reconocerle una existencia de autor. De ahí en más, la iniciativa del curador será diferente. (Chaumier 2013, 289)

Estas consideraciones generales hacia el visitante, se conjugan, en el caso que nos ocupa, con la intención pedagógica por parte de representantes de pueblos originarios, de desarrollar una estrategia de construcción de identidad, donde el patrimonio exhibido es el elemento clave de su despliegue discursivo.

\section{El Museo de La Plata: un museo del siglo XIX}

13 El Museo de La Plata fue fundado por Francisco Pascasio Moreno (1852-1919) en 1884 y desde 1906 pertenece a la Universidad Nacional de La Plata. Este museo es un exponente emblemático de las ideas que guiaron el nacimiento de los grandes museos de ciencias del siglo XIX. Su concepción, plasmada tanto en su planta edilicia, segmentaciones disciplinarias, organización de su recorrido y formas expositivas, reproduce las características propias del museo decimonónico, vitrinas colmadas de piezas organizadas 
según clasificaciones taxonómicas y donde se podía apreciar la grandeza patrimonial de la Nación (Moreno 1890; Teruggi 1994).

Al igual que muchos museos de Historia Natural de la época, tanto de Europa como América, las colecciones antropológicas ocuparon el último escalón del recorrido evolutivo. En este contexto, la cultura material de los grupos etnográficos exponía las primeras etapas del desarrollo de la humanidad, en las que el pasaje de lo primitivo a la civilización respondía al esquema evolucionista unilineal. Estas culturas, catalogadas según grados de desarrollo, estaban destinadas a desaparecer, y el rescate y registro de objetos coleccionables resultó una práctica de emergencia. A partir de allí, los museos acompañaron los procesos de nacionalización e incrementaron sus colecciones en contextos de expansión colonialista (Podgorny 2005; Podgorny y Lopes 2008; Farro 2009). Como dijimos, desde hace algunas décadas los museos se encuentran en un proceso de revisión de sus presupuestos y las reflexiones disciplinares en cuanto a los modos de representación del conocimiento antropológico se instala como uno de los debates centrales.

En los últimos años, se vienen desarrollando en el Museo de la Plata una serie de acciones tendientes a configurar nuevas políticas de gestión. La renovación de sus propuestas expositivas, el retiro de exhibición de los restos humanos y cuerpos momificados de origen americano y su restitución a las comunidades reclamantes, la apertura de espacios restringidos para la ejecución de prácticas rituales, las iniciativas en torno a los estudios de público para comprender mejor la experiencia de la visita, son algunos ejemplos de programas de acción que, aunque a veces de carácter coyuntural, van nutriendo el diseño de nuevas políticas para la exhibición y gestión del patrimonio. Esta dinámica se conjuga con los valores institucionales heredados e históricos. Así, una constelación de interpretaciones toma vigencia en contextos específicos, para diversos actores y grupos sociales que ejercen en torno al patrimonio una apropiación diferencial, generando un campo de disputas económicas, políticas y simbólicas (García Canclini 1999; Monge Martínez 2010).

\section{Espejos Culturales: la sala de exhibición de etnografía del Museo de La Plata}

16 La Sala de Etnografía es una exhibición de carácter permanente reinaugurada en marzo de 2007. Bajo el título Espejos Culturales busca poner en valor la diversidad sociocultural en sus variadas expresiones (fig. 1, 2 e 3). Este concepto atraviesa toda la propuesta museográfica. Se dedica especial atención a los pueblos originarios de la Argentina y se busca dar un mensaje sobre su presencia actual, su riqueza cultural y sus derechos, a través de diferentes recursos (mapas, videos, estadísticas, leyes, fotografías) y estrategias comunicativas. La puesta museográfica alude a los procesos históricos que configuran un presente de reafirmación en el que persiste una cosmovisión particular profundamente ligada a la naturaleza, la tierra y el universo.

17 El término etnografía se refiere, para este caso a la "etnografía tradicional" entendida como la descripción exhaustiva de los diversos modos de vida. Si bien la etnografía hace por lo menos dos décadas ha ingresado fuertemente en el análisis de la sociedad compleja, los conjuntos temáticos de la sala aparecen vinculados con las colecciones de la División Etnografía del Museo, en su mayoría pertenecientes a las primeras décadas de la historia 
del museo hasta aproximadamente los años 1950-1960, y con algunos ingresos aislados en los años siguientes.

Desde una perspectiva antropológica y antiesencialista, la Sala de Etnografía - Espejos Culturales - propone al visitante una reflexión actualizada sobre el valor de la diversidad cultural y cuestiona ciertos prejuicios y creencias instaladas en el imaginario social, tales como la escala de progreso con la que son juzgados los pueblos originarios (culturas primitivas y culturas civilizadas); su ausencia o extinción definitiva; su reducción a zonas lejanas o del interior del país; su homogeneización, entre otros.

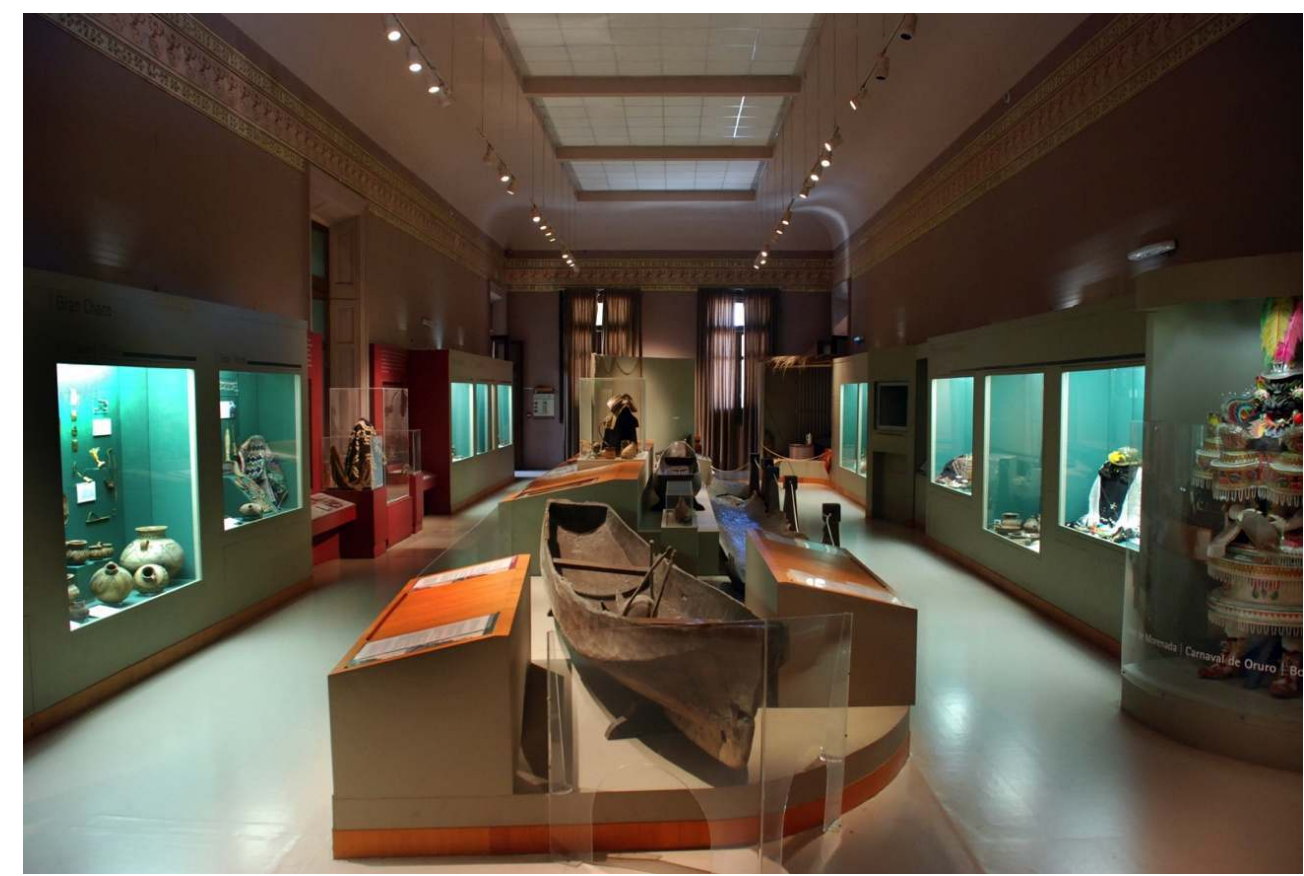

Fig. 1 - Vista general de la Sala de Etnografía - Espejos Culturales - del Museo de La Plata, 2006 Fotografía: Pilar Ungaro

El guión museológico se organiza a partir de tres criterios conceptuales que se yuxtaponen en el espacio expositivo y son el resultado del análisis relacional del conjunto de presupuestos teóricos, a saber: un primer criterio espacial y geográfico; un segundo criterio delimitado por la precedencia étnica y a la cual se acoplan conjuntos temáticos que agrupan los objetos por afinidad de actividades y contextos de uso; finalmente, un tercer criterio organizativo supera el anclaje en objetos específicos para reflexionar sobre la identidad, los derechos, la situación actual de los grupos, su cosmovisión, entre otros conceptos.

El valor de la diversidad atraviesa toda la propuesta museográfica que intenta promover un desplazamiento expresado como "de la tierra al territorio", "del objeto al sujeto", "del pasado al presente", "de una identidad congelada en el tiempo a una identidad dinámica", "del etnocentrismo a la diversidad cultural" (Reca 2016). 


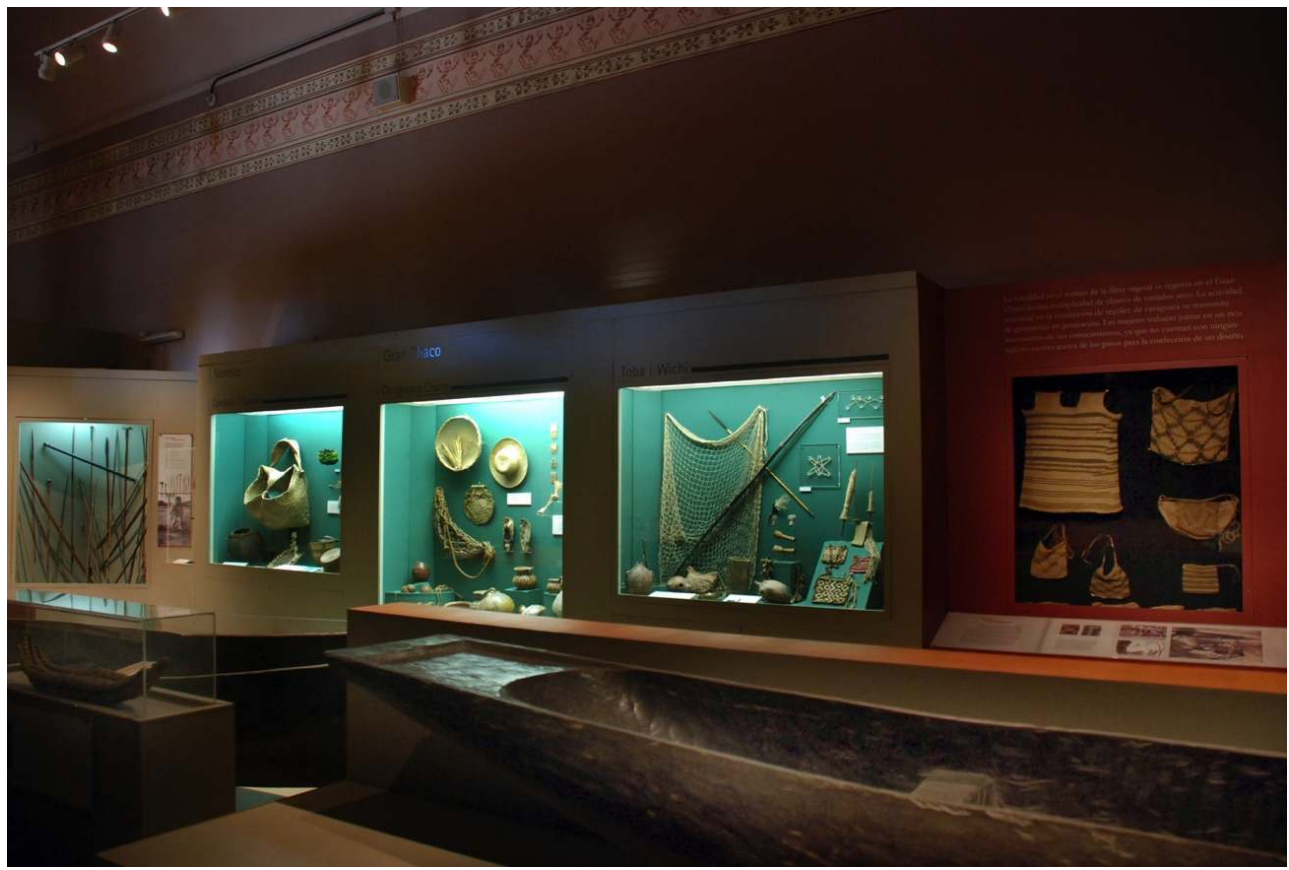

Fig. 2 - Sector Gran Chaco de la Sala de Etnografía - Espejos Culturales - del Museo de La Plata, 2006

Fotografía: Pilar Ungaro

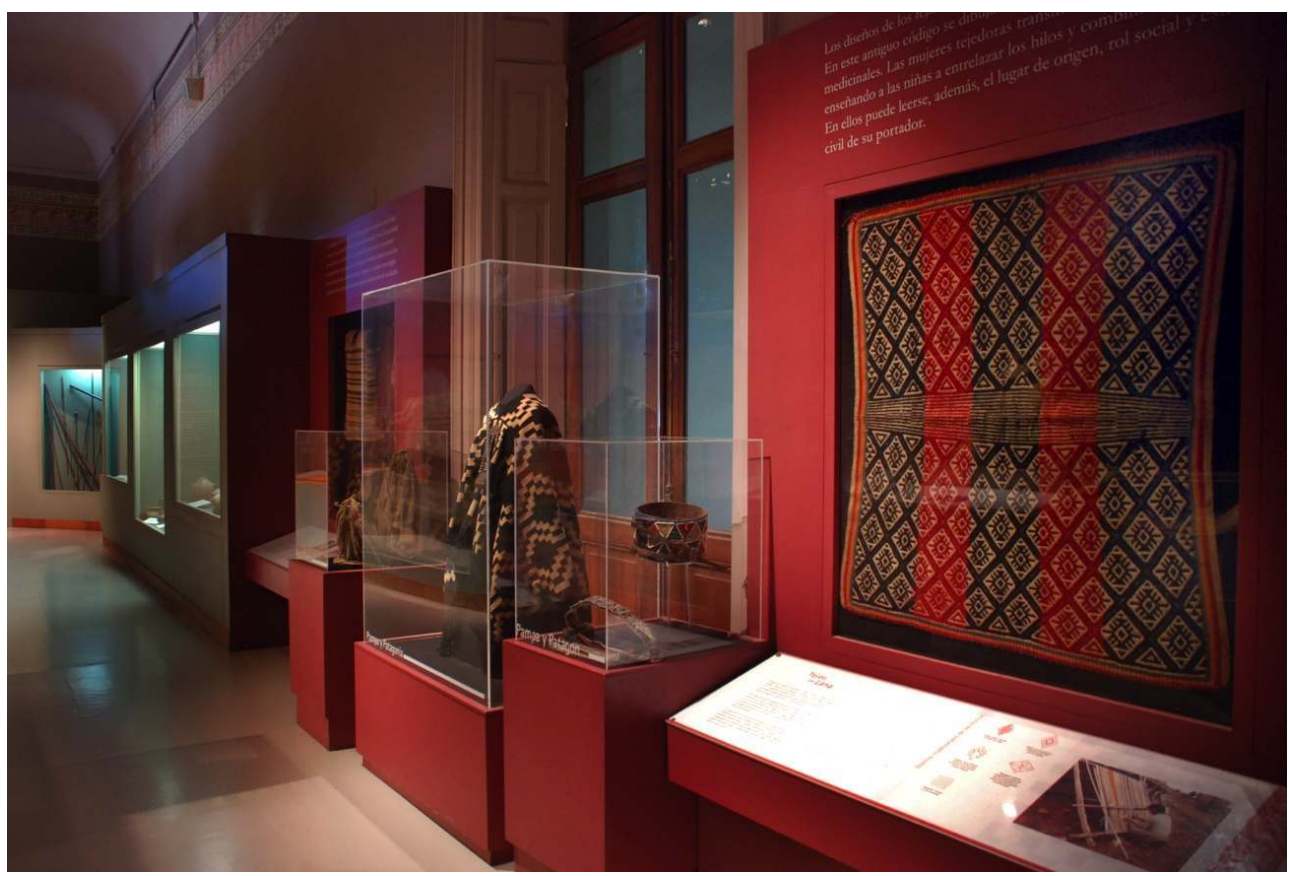

Fig. 3 - Sector Patagonia de la Sala de Etnografía - Espejos Culturales - del Museo de La Plata, 2006 Fotografía: Pilar Ungaro

\section{Contexto y consideraciones metodológicas}

21 Según datos oficiales del último censo del año 2010 (Instituto Nacional de Estadística y Censos de la República Argentina - INDEC), en la provincia de Buenos Aires habitan 299.311 miembros de pueblos originarios. El mismo censo arrojó datos que estiman que la 
ciudad de La Plata, junto con Buenos Aires y su conurbano, albergan el 40\% de la población indígena del país (Ministerio de Educación y Deportes de la Nación 2016), siendo actualmente la región con mayor cantidad y diversidad de pueblos originarios del país (Tamagno y Maidana 2011).

Los números estimados por el Consejo de Comunidades Indígenas de La Plata, donde se reúnen los pueblos Qom, Guaraní, Kolla, Aymara y Mapuche, llegan a un aproximado de diez mil indígenas en la ciudad. Una de las organizaciones formales es el Centro Wawawasi, «es una organización sin fines de lucro donde los niños de la comunidad Kolla asisten con el objetivo de fortalecer y preservar su identidad» $»^{1}$. Es un Centro integral indígena donde a través del desarrollo de diversos talleres se busca fortalecer y preservar la identidad y tradición de los pueblos originarios. Las principales tareas llevadas adelante por el Centro son la enseñanza del quechua y guaraní, talleres de cerámica, tejido y horticultura. Alrededor de 50 niños y niñas asisten al Centro y pertenecen, en su mayoría, a la comunidad kolla.

La principal encargada del Centro junto a otras mujeres es María Ochoa Torres cuyo nombre en lengua quechua es Illa Ñan, nacida en Perú y quien hace más de 20 años vive en la ciudad de La Plata. Además, María Ochoa Torres es una de los miembros de la comunidad kolla platense.

María Ochoa Torres comenzó a participar en distintos eventos del Museo como, por ejemplo, la circunstancia de las restituciones y encuentros ceremoniales/rituales planificados. Además, es alumna de la carrera de Antropología de la Facultad de Ciencias Naturales y Museo de la Universidad Nacional de La Plata. Como estudiante de Antropología, María Ochoa Torres comenzó un contacto más cercano con una de las integrantes del equipo docente en una de las materias de la licenciatura en Antropología. En el año 2015 María Ochoa Torres solicitó a nuestro equipo la colaboración para trabajar conjuntamente en la discusión y diseño de un censo que reflejara las condiciones de vida de las comunidades originarias de distintos orígenes que habitan en la ciudad de La Plata. Esto motivó la visita nuestra al Centro Wawawasi en varias oportunidades, participando de reuniones conjuntas con miembros de otras comunidades de pueblos originarios que también habitan en La Plata y alrededores. En ese marco surgió la iniciativa de realizar visitas guiadas en la Sala de Etnografía Espejos Culturales del Museo con niños/as que asisten al Centro Wawawasi.

Las visitas guiadas a la Sala de Etnografía se realizaron entre los años 2015 y 2017. En dichas visitas participaron María Ochoa Torres junto a un grupo de entre seis y diez niños/as con un rango de edad entre los cuatro y los siete años. Las visitas al Museo y los objetivos que éstas tienen se engloban en la estrategia política de María Ochoa Torres como representante y líder del Centro Wawawasi. Entre estos objetivos se encuentra el propósito de brindarle a los niños y niñas la oportunidad de visitar la sala y de escuchar las explicaciones y sentidos dados a los objetos expuestos, tanto a partir del discurso curatorial como de los propios significados y explicaciones de María Ochoa Torres.

Las visitas consistieron en el recorrido de la Sala de Etnografía, el cual siguió el planteo propuesto por el guión museográfico. Las tres visitas a la sala de exhibición circunscribieron una experiencia situada en la que se articularon las diversas miradas. Las integrantes del equipo de investigación cumplíamos un rol específico de orientación y diálogo: algunas observábamos la experiencia, mientras que otras oficiábamos de guías en determinados sectores de la sala. La actividad que mediaba entre los distintos discursos 
consistió en la descripción y explicación de los objetos culturales expuestos y sus contextos, a partir del discurso curatorial. María Ochoa Torres cumplió, a lo largo de todo el recorrido, un "doble rol", alternando su función de guía y de visitante en distintos sectores de la sala. Al finalizar el recorrido, incorporamos una actividad que consistió en la realización individual de dibujos de aquellos objetos que a los niños/as más les gustaron o llamaron la atención de la sala.

La experiencia en la Sala permitió el intercambio y diálogo entre el discurso curatorial y los saberes de María Ochoa Torres acerca de los objetos culturales expuestos. En ciertos sectores, luego de explicar los objetos a partir del discurso curatorial, María Ochoa Torres tomaba la voz y complementaba nuestras explicaciones con sus propias maneras de ver y dar significado a lo expuesto. En otros sectores, María Ochoa Torres se disponía directamente a describir los usos culturales de los objetos etnográficos. Esto último se ve ejemplificado en el sector de "Pampa y Patagonia", en el cual María Ochoa Torres tomó como referencia un poncho mapuche para hablar sobre el significado de los tejidos. En esta oportunidad, comenzó a explicarle a los niños/as acerca del significado de los dibujos del poncho, hizo énfasis en una cruz de seis puntas que indicaba los puntos cardinales. En el centro de esta cruz estaba el sol, "el centro del cosmos". En este mismo sector comentó que los pueblos mapuches habían logrado cultivar plantas para comer y desarrollar el tejido a diferencia de los pueblos cazadores de Tierra del Fuego. A partir de estos ejemplos, pudimos observar que María Ochoa Torres se sentía más cómoda hablando de temas vinculados a la alimentación y la cosmovisión de los pueblos originarios en general, tomando como referencia su cultura andina, en lugar de hablar del uso de los objetos descrito en la sala.

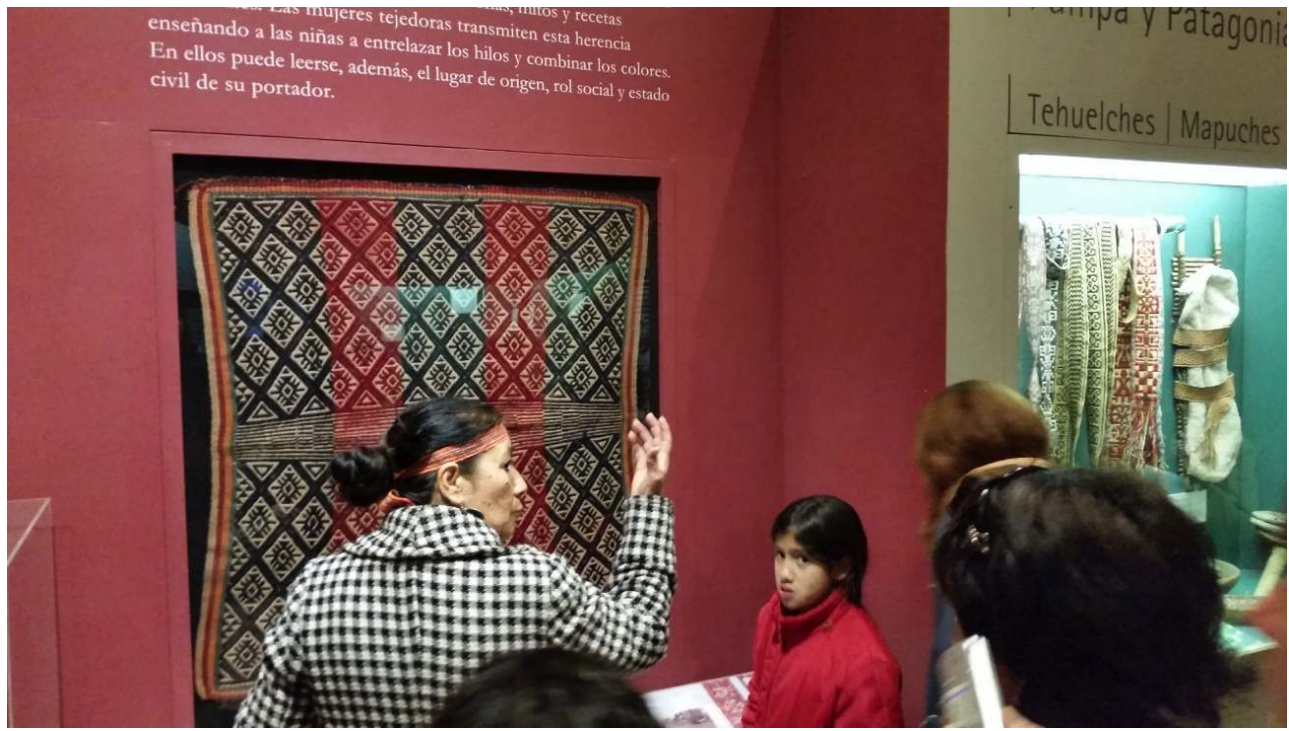

Fig. 4 - Sector Patagonia/textiles de la Sala de Etnografía - Espejos Culturales - del Museo de La Plata. María Ochoa Torres explica a los niños/as el sentido simbólico de las guardas, 2015 (C) Museo de La Plata

Durante la visita, los niños y niñas fueron muy participativos, algunos de ellos señalaban los objetos por las funciones que tenían en relación a las actividades que conocían, por ejemplo "las redes para la pesca", "las pezuñas de cabra para un instrumento", "las flechas para cazar al pececito". En el sector Andino los niños/ñas hablaban sobre las ceremonias, el maíz, la chicha. Al final de la visita se dispusieron a realizar dibujos de los objetos que más les habían gustado o llamado la atención de la sala. En la misma Sala de 
Etnografía, nos sentamos en el piso junto a los niños y niñas, que con crayones y afiches, pintaron canoas, instrumentos musicales, tejidos, canastos, entre otros. Luego, como cierre de la visita, realizamos una puesta en común.

En el intervalo entre visitas realizamos una entrevista en profundidad a María Ochoa Torres en el ámbito del museo, generando un espacio de interacción y reflexividad acerca de la intención y sentido de los encuentros y el valor que María Ochoa Torres les otorga. ${ }^{2}$ Considerando la entrevista como «una situación cara a cara donde se encuentran distintas reflexividades pero, también, donde se produce una nueva reflexividad. Es decir que, la entrevista es una relación social a través de la cual se obtienen enunciados y verbalizaciones en una instancia de observación directa y de participación» (Guber 2001,75).

30 Esta instancia no constituyó un espacio de planificación ni estructuración de las subsiguientes visitas - manteniendo el objetivo de una apropiación libre y espontánea sino que permitió conocer mejor las intenciones que movilizaban el encuentro. En esta modalidad de trabajo prevaleció el encuentro y la participación desde los inicios de la investigación, de manera que la construcción conjunta surgiera del proceso de producción de sentido en una etnografía “doblemente reflexiva” (Dietz 2011).

31 Entre los ítems que fueron aludidos por María Ochoa Torres se destacan: el valor del trabajo con los niños, la importancia de la visita en cuanto al material que ofrece, la oportunidad de destacar los conocimientos ancestrales, la reciprocidad como base del encuentro y la expectativa de desarrollar estrategias a mediano plazo. También se aludió a algunos conocimientos y saberes que no están presentes en los mensajes de la sala, algo que pudimos corroborar en la experiencia. Algunos fragmentos de la entrevista con María Ochoa Torres rescatan lo mencionado:

Así es, así, porque si nosotros las semillitas que tenemos alrededor no las cultivamos, no van a crecer. Entonces es importante que podamos hacerlo con ellos, porque el grande de por sí se contaminó mucho con la ciudad, entonces cuesta mucho trabajar con ellos, entonces los que tenemos la misión de estar hoy en vida y tener la palabra que nos da la Madre Tierra Pachamama, consideramos que es importante con los jóvenes y con los niños, sin descuidar al adulto, por supuesto.

Sí, sí, la idea es que sume y me parece bastante interesante. Nosotros dentro de la problemática que afrontamos, nos interesarían ambos temas, nos interesaría poder traer a los niños y que también ustedes conozcan nuestro espacio. Muy lindo no está ahora, pero tenemos esperanza de que sí. Y el tema es el transporte para traer a los niños, y ya ellos, desde más antes me venían diciendo "Mari no volvimos más al Museo, vos dijiste que sí" entonces ellos ya están preparaditos como para poder venir y hacerlo, sí.

El segundo encuentro fue grabado en su totalidad, con el consentimiento de María Ochoa Torres, lo cual permitió, a posteriori, analizar por un lado, los niveles de referencialidad en cuanto a los sectores, los objetos y los temas, propuestos en la sala de exhibición. ${ }^{3}$ Por otro, analizar el contenido de los mensajes y deconstruir el relato curatorial identificando puntos de conexión, ausencias, acuerdos y desacuerdos otorgando contenido a la apropiación diferencial por parte del grupo. Se implementó el análisis del contenido discursivo a través de la identificación de categorías según los temas propuestos y su relación con los sectores del recorrido. Los temas tratados con mayor frecuencia y de forma reiterada durante la visita a la sala fueron: cosmovisión, relación con la naturaleza, alimentación, técnicas de confección artesanal, incorporando conexiones simbólicas y destacando el valor de las relaciones sociales recíprocas. Se destacan aquí algunos ejemplos: 
Cuando tenemos muchas preguntas y no sabemos la respuesta podemos leer acá. Este es un ñandú para nosotros, algunos le dicen la cigüeña, tendrán diferentes nombres, ésta ave existía mucho en esta zona y servía para alimento también.

Ay, miren justo que estamos hablando de la comidita y acá está la comidita, rica, eh. Acá están las papas, los grandes papines, las grandes variaciones de papa, de las cuales nosotros hablábamos la vez de pasada, de no menos de 2.200 variedades de papas y de maíces, también, ¿sí? Hablábamos de 1.600 variedades de maíces que actualmente quedan 800 nada más... Son con diferentes colores, de valor nutritivo, y como también para medicina. Porque toda la alimentación nuestra tenía que ver con la forma preventiva, y cada color simboliza determinados nutrientes [...].

[...] la persona que no se sabe alimentar por sí sola no se puede considerar en un crecimiento, en un adulto. Porque también cuando son grandes tienen que alimentar a su familia, van a tener una pareja, una esposa, y hay que saber cazar, sembrar, buscar alimento para esa persona, porque eso siempre se consideraba, cuando ya podías cazar, podías sembrar y tener una buena cosecha ya estabas preparado para formar tu nueva familia.

[...] Cada dibujo que vemos acá está representando el cosmos, porque nuestra cultura es cósmica, acá tenemos chacana, tenemos la fuerza del Inti que está representado en ese llamado dibujo, pero que está representando las fuerzas energéticas que armonizan con nuestro ser ¿Sí? Así que ahí lo podemos observar.

Entonces iban desarrollando muchas actividades para el bien de la población, para el bien de la condición de cada persona.

Y muy trabajado todo en cuero. Y como ustedes pueden observar, también se cose, ya se conocía el coser, el unir cosas, ¿Si? Entonces iban desarrollando muchas actividades para el bien de la población, para el bien de la condición de cada persona.

[...] y el plástico hace daño porque neutraliza la energía de la madre tierra, de la Pachamama, por eso no debemos usar zapato de plástico, porque nos aísla de la energía. Y esto sirve, se recibe la energía de la madre tierra. Acá tenemos arriba peines, son peines ¿sí? ¿Qué más ven?

\section{Consideraciones finales}

Desde hace al menos diez años en el contexto de los museos de Argentina comienza a visualizarse un ámbito concreto para las prácticas "descolonizadoras", desplegadas en espacios museales antes inaccesibles, así como un mayor empoderamiento por parte de descendientes de pueblos originarios, a través de reclamos de repatriación y restitución, en el marco del ejercicio de un derecho sobre el patrimonio (Reca 2012). Estas políticas participativas, ya consolidadas en países como Estados Unidos, Canadá, Australia y Nueva Zelandia, estuvieron acompañadas del análisis crítico de la antropología centrado en la construcción y representación de la Otredad y la cosificación de las culturas en las salas de exhibición (Clifford 1985; Ames 1991; Karp 1991). Particularmente en Latinoamérica, se pueden registrar experiencias realizadas en museos universitarios de características similares al Museo de La Plata, como por ejemplo los trabajos de Cury, Vasconcellos y Ortiz (2012), en el Museu de Etnologia y Arqueologia de São Paulo (Brasil), y Vasconcellos, Funari y Carvalho (2015), entre otros. En Argentina se han desarrollado pocas experiencias, entre las que se pueden nombrar las llevadas a cabo en el Museo Etnográfico de Buenos Aires (Pegoraro y Alfonsina Elías 2010).

Partimos de la idea de que el patrimonio es una construcción social cuyos sentidos emergen en contextos socio-históricos específicos, y que dicha construcción requiere de la participación de diversos actores sociales/intérpretes que aportan a la construcción de un modelo dialógico, dejando espacio a la controversia, la contradicción y la multiplicidad 
de miradas (Reca 2016). La exhibición constituye, así, uno de los lugares de activación de la memoria y desde un punto de vista comunicacional es fuente de un amplio universo de representaciones.

Sabemos que toda visita a una exhibición conlleva un proceso selectivo de construcción de sentido, más o menos explícito, más o menos orientado en un recorrido pautado y en el marco de una experiencia situada. En este caso particular, esta apropiación diferencial en relación a la propuesta curatorial se sustenta y está orientada por los saberes comunitarios que María Ochoa Torres pone en juego durante el recorrido, desempeñando el doble rol de visitante-guía, para ejercer su "pedagogía de la identidad". Objetos, formas de confección, materias primas, relación con la madre tierra, decoración, pinturas, cosmovisión, entre otros temas, desdibujan los límites étnicos que forman parte de las clasificaciones etnográficas tradicionales para fortalecer la distinción nosotros/ellos/ otros. Esta situación se ve en el recorrido cuando María Ochoa Torres toma como referencia los objetos etnográficos de diversas culturas (canoas fueguinas, poncho mapuche, máscaras chané, etc.) y orienta sus comentarios aludiendo a los saberes que le resultan conocidos, sin hacer referencia a la procedencia. focalización en el objeto y sus técnicas, decoraciones o funciones, los saberes tradicionales, y su contenido simbólico. A su vez podemos decir que hay diferentes recortes en cuanto a temas, objetos y contextos. Los temas que prevalecen se refieren a la cosmovisión, la alimentación, el trabajo manual, ceremonias y son recurrentes ante muy variadas posibilidades de anclaje, perdiendo, como dijimos, especificidad étnica. La "visión del mundo" propuesta tiende a la homogeneización de las culturas y al fortalecimiento de un nosotros confrontado en forma implícita y/o explícita a un ellos también indiferenciado. Así, en las intervenciones de María Ochoa Torres prevalecen la auto-referencia hacia un nosotros que desdibuja los límites territoriales aunque en algún caso toma la forma de "lo andino".

37 En el análisis acerca de la relación de su construcción discursiva con el contenido de la Sala de Etnografía del Museo de La Plata, vemos que su presentación toma relevancia en relación a su objetivo pedagógico hacia los niños/as, más allá de la certeza del conocimiento brindado. La eficacia de su estrategia comunicativa está anclada en su presencia según el vínculo preestablecido con el grupo y el contexto de autoridad que ostenta el Museo para establecer conexiones significativas con el patrimonio exhibido. El Museo se abre así a la ambigüedad, a la polifonía; recorre y atraviesa nuevos circuitos comunicativos, deconstruye los supuestos curatoriales, en algún caso los fortalece, los recrea, haciendo de la exhibición una obra abierta.

Esta apropiación diferencial del patrimonio, que "quietecito en la vitrina" ostenta la condición de autenticidad desde el momento de su recolección, nutre otras explicaciones, otras interpretaciones, otras intenciones. El patrimonio se convierte, en esta secuencia, en un recurso pedagógico que "anima" actualizaciones de sentido. Desde un punto de vista semiótico, esta activación actualiza y pone en vigencia su eficacia simbólica en el contexto particular en que se da la experiencia del encuentro. Se trata de una experiencia de carácter "holístico" en la que intervienen aspectos emocionales, cognitivos, comportamentales y muchas veces, estos encuentros informales son el punto de partida para el diseño de futuros programas de acción aplicados, perdurables, sistemáticos, y mutuamente beneficiosos. Para esto es necesario generar los espacios que permitan el 
diálogo y la negociación de saberes que consolidan el carácter comprometido y dinámico de los museos participativos.

\section{BIBLIOGRAFÍA}

Ames, Michael M. 1991. “Biculturalism in Exhibitions.” Museum Anthropology 15 (2): 7-15.

Asensio Brouard, Mikel, Elena Pol Méndez, y Mario Carretero. 2002. Nuevos Escenarios en Educación. Aprendizaje Informal sobre el Patrimonio de los Museos y la Ciudad. Buenos Aires: Aique.

Asensio Brouard, Mikel. 2015. "El Aprendizaje Natural, la Mejor Vía de Acercarse al Patrimonio." Educatio Siglo XXI 33 (1): 55-82.

Ausubel, David, Joseph Novak, y Helen Hanesian. 1983. Psicología Educativa. Un Punto de Vista Cognoscitivo. México: Editorial Trillas.

Chaumier, Serge. 2013. "El Público, ¿Actor de la Producción de la Exposición? Un Modelo Dividido entre Entusiasmo y Reticencias.” En El Museo y sus Públicos. El Visitante Tiene la Palabra, ed. Jacqueline Edelman, Mélanie Roustan, y Bernadette Goldstein, 279-289. Buenos Aires: Ariel, Arte y Patrimonio, y Fundación TyPA.

Clifford, James. 1985. "Objects and Selves: An Afterword." En Objects and Others. Essays on Museums and Material Culture. Vol. 3. History of Anthropology, 236-246. Madison: University of Wisconsin Press.

Clifford, James. 1991. "Sobre la Autoridad Etnográfica." En El Surgimiento de la Antropología Posmoderna, ed. Clifford Geertz, James Clifford y Carlos Reynoso (compilación), 39-77. México: Gedisa.

Cury, Marília Xavier, Camilo de Mello Vasconcelos, y Joana Montero Ortiz, coords. 2012. Questões Indígenas e Museus: Debates e Possibilidades. Coleção Museu Aberto. São Paulo: ACAM Portinari, Museu de Arqueologia e Etnologia da Universidade de São Paulo e Secretaria de Estado da Cultura.

Díaz Barriga Arceo, Frida. 2003. "Cognición Situada y Estrategias para el Aprendizaje Significativo.” Revista Electrónica de Investigación Educativa 5 (2): 105-117.

Dietz, Gunther, y Laura Selene Mateos Cortés. 2010. “La Etnografía Reflexiva en el Acompañamiento de Procesos de Interculturalidad Educativa: Un Ejemplo Veracruzano.” Revista Cuicuilco 17 (48): 107-131.

Dietz, Gunther. 2011. "Hacia una Etnografía Doblemente Reflexiva: Una Propuesta desde la Antropología de la Interculturalidad.” AIBR - Revista de Antropología Iberoamericana 6 (1): 3-26.

Farro, Máximo. 2009. La Formación del Museo de La Plata. Coleccionistas, Comerciantes, Estudiosos y Naturalistas Viajeros a Fines del Siglo XIX. Rosario: Prohistoria Ediciones.

Fontal Merillas, Olaia. 2016. "Educación Patrimonial: Retrospectiva y Prospectivas para la Próxima Década.” Estudios Pedagógicos XLII (2): 415-436. 
García Canclini, Néstor. 1999. “Los Usos Sociales del Patrimonio Cultural.” En Cuadernos, Patrimonio Etnológico: Nuevas Perspectivas de Estudio, ed. Encarnación Aguilar criado, 16-33. Sevilha: Consejería de Cultura, Junta de Andalucía.

Guber, Rosana. 2001. La Etnografía. Método, Campo y Reflexividad. Bogotá: Grupo Editorial Norma. Gutiérrez Estévez, Manuel. 1998. "Diálogo Intercultural en el Museo: Silencios, Malentendidos y Encasillados.” Anales del Museo de América (6): 205-215.

Hall, Stuart. 2003. “Introducción: ¿Quién Necesita Identidad?” En Cuestiones de Identidad Cultural, ed. Stuart Hall, y Paul du Gay, 13-40. Buenos Aires: Amorrortu.

Hernández Hernández, Francisca. 2011. "Museo Dialógico y Comunicación Social.” En Documentos de Trabajos: El Museo Dialógico y la Experiencia del Visitante, 77-85. [s.l.]: ICOM. http:// network.icom.museum/fileadmin/user_upload/minisites/icofom/pdf/ISS\%2040\%20Working\% 20Papers.pdf

Instituto Nacional de Estadística y Censos de la República Argentina (INDEC). 2010. https:// www.indec.gov.ar/

Karp, Ivan. 1991. “Culture and Representation.” En Exhibiting Cultures: The Poetic and Politics of Museum Display, ed. Ivan Karp, y Steven Lavine, 11-24. Washington: Smithsonian Institution Press. Ministerio de Educación y Deportes de la Nación. 2016. Indígenas en Clave Urbana Intercultural en el Conurbano y La Plata. Pueblos Indígenas en la Argentina: Historias, Cultura, Lenguas y Educación. Pueblos indígenas en la Argentina, 5. Ciudad Autónoma de Buenos Aires: Ministerio de Educación y Deportes de la Nación.

Monge Martínez, Fernando. 2010. "De Museos del Saber a Museos de los Pueblos. El lugar de los Antropólogos.” En Dilemas Éticos en Antropología. Las Entretelas del Trabajo de Campo Etnográfico, ed. Margarita del Olmo Pintado, 125-144. Madrid: Trotta.

Moreno, Francisco Pascasio. 1890. El Museo de La Plata. Rápida Ojeada sobre su Fundación y Desarrollo. La Plata: Imprenta y Talleres del Museo de La Plata.

Navarro Rojas, Óscar. 2011. “Ética, Museos e Inclusión: Un Enfoque Crítico.” Revista Museo y Territorio (4): 49-59.

Pegoraro, Andrea y Mariana Alfonsina Elías. 2010. “Documentación de Colecciones Etnográficas: Los Desafíos de los Tiempos Actuales. El Caso de las Colecciones Etnográficas del Museo Etnográfico 'Juan B. Ambrosetti' de la Universidad de Buenos Aires.” En Actas del $1^{\circ}$ Congreso Nacional de Museos Universitarios. Red de Museos de la Universidad Nacional de La Plata. http:// sedici.unlp.edu.ar/bitstream/handle/10915/41723/Documento_completo.pdf?sequence=1

Podgorny, Irina, y Maria Margaret Lopes. 2008. El Desierto en una Vitrina. Museos e Historia Natural en la Argentina, 1810-1890. México: Ed. LIMUSA.

Podgorny, Irina. 2005. “La Mirada que Pasa: Museos, Educación Pública y Visualización de la Evidencia Científica.” Historia, Ciências, Saúde - Manguinhos vol 12 (suplemento): 231-264.

Prats, Llorenç. 2005. “Concepto y Gestión del Patrimonio Local." Cuadernos de Antropología Social (21): 17-35.

Reca, María Marta. 2012. "Reflexiones en Torno al Patrimonio Etnográfico en los Museos y sus Contextos de Significación.” En Questões Indígenas e Museus: Debates e Possibilidades, coord. Marília Xavier Cury, Camilo de Mello Vasconcelos, y Joana Montero Ortiz, 112-128. Coleção Museu Aberto. São Paulo: ACAM Portinari, Museu de Arqueologia e Etnologia da Universidade de São Paulo e Secretaria de Estado da Cultura. 
Reca, María Marta. 2016. Antropología y Museos. Un Diálogo Contemporáneo con el Patrimonio. Buenos Aires: Biblos.

Tamagno, Liliana Ester, y Carolina Andrea Maidana. 2011. "Grandes Urbes y Nuevas Visibilidades de la Diversidad." Revista Brasilera de Estudos Urbanos e Regionais 13 (1): 51-61.

Teruggi, Mario. 1994. Museo de la Plata. 1888-1988. Una Centuria de Honra. La Plata: Fundación Museo de La Plata Francisco Pascasio Moreno.

UNESCO. 2003. Convención para la Salvaguardia del Patrimonio Cultural Inmaterial. París: UNESCO.

Valdés Sagüés, María del Carmen. 1999. La Difusión Cultural en el Museo: Servicios Destinados al Gran Público. Gijón: Ediciones Trea

Vasconcellos, Camilo de Mello, Pedro Paulo A. Funari, y Aline Carvalho, coords. 2015. Museus e Identidades na América Latina. São Paulo: Ed. Annablume.

\section{NOTAS}

1. “Wawawasi. Centro Integral Indigena": https://www.facebook.com/pages/category/ Community-Organization/WawawasiCentro-Integral-Indigena-1901863699952595/ (consultado en Abril 9, 2019).

2. Entrevista a María Ochoa Torres, realizada por María Marta Reca y el equipo de investigación, el día 3 de Noviembre de 2016 en el Museo de La Plata.

3. El segundo encuentro con María Ochoa Torres se llevó a cabo el día 1 de Diciembre de 2016, organizado por el equipo de investigación en la Sala de Etnografía "Espejos Culturales" del Museo de La Plata.

\section{RESÚMENES}

En las últimas décadas los museos experimentan un cambio paradigmático que impacta en su accionar político institucional y educativo. En particular, las colecciones antropológicas son motivo de análisis críticos de la mano de las perspectivas hermenéuticas y constructivistas en el análisis de la cultura, legitimado por la evidente vinculación entre el patrimonio, memoria e identidad. El objetivo de este artículo es reflexionar sobre las potencialidades educativas del patrimonio etnográfico a partir de un programa de visitas a la Sala de Etnografía del Museo de La Plata (Buenos Aires, Argentina). Se adoptó un enfoque etnográfico-cualitativo, implementando prácticas de observación y entrevistas en profundidad, y la posterior aplicación de técnicas de análisis de contenido. En dicha experiencia se pone de manifiesto una práctica situada de resignificación del patrimonio por parte de representantes de culturas originarias.

Over the last decades museums have experienced a paradigmatic shift with impacts on their educational, political and institutional agendas. Anthropological collections in particularly have been subject to critical analysis from the hermeneutic and constructivist perspectives of cultural studies - their work strengthened by the bond between heritage, memory and identity. The purpose of this article is to consider the educational potential of ethnographic heritage on the 
basis of a visit program at Sala de Etnografía of the Museo de La Plata (Buenos Aires, Argentina). An ethnographic-qualitative focus was adopted, including observation practices, as well as in-depth interviewing, and the subsequent content analysis techniques. A heritage re-signification situated practice was highlighted by such experience, with the participation of aboriginal cultures representatives.

\section{ÍNDICE}

Palabras claves: Museo de La Plata, educación patrimonial, colección etnográfica, identidad, comunidades

Keywords: heritage education, ethnographic collection, identity, community

\section{AUTORES}

\section{MARÍA MARTA RECA}

Coordinadora de la Unidad de Conservación y Exhibición del Museo de La Plata (Facultad de Ciencias Naturales y Museo, Universidad Nacional de La Plata, Argentina) desde 2002. Profesora adjunta de la cátedra "Teoría Antropológica" de la carrera de Antropología de la Facultad de Ciencias Naturales y Museo de la Universidad Nacional de La Plata. Desde el 2014 se desempeña, en la misma Universidad, como directora del proyecto de investigación "Las Formas de Apropiación y Representación del Patrimonio Antropológico en Museos". Ha dictado cursos de posgrado y charlas, y publicado artículos en temas de museología, patrimonio, antropología y cuestiones indígenas, estudios de público, documentación de colecciones, entre otros. Museo de La Plata. Paseo del Bosque S/N (1900), La Plata, Buenos Aires, Argentina, mmreca@fcnym.unlp.edu.ar

\section{ANA INÉS CANZANI}

Licenciada en Antropología por la Facultad de Ciencias Naturales y Museo (FCNyM) de la Universidad Nacional de La Plata (Argentina). Estudiante del doctorado en Ciencias Naturales de la FCNyM con el plan de tesis "Patrimonio Etnográfico y Museos. Colecciones del Museo de La Plata y su Activación por parte de Pueblos Originarios". Becaria de investigación de la Universidad Nacional de La Plata. Miembro del proyecto "Las formas de Apropiación y Representación del Patrimonio Antropológico en Museos” (Programa de Incentivos - FCNyM, Universidad Nacional de La Plata).

Museo de La Plata, Paseo del Bosque S/N (1900), La Plata, Buenos Aires, Argentina, anacanzani@yahoo.com.ar

\section{MARÍA CECILIA LUZ DOMÍNGUEZ}

Licenciada en Antropología por la Facultad de Ciencias Naturales y Museo (FCNyM) de la Universidad Nacional de La Plata (Argentina). Estudiante del doctorado en Ciencias Naturales de la FCNyM con el plan de tesis "Las Representaciones Sociales en torno al Patrimonio y los Sitios de Memoria. El Caso de los Sitios Mariani-Teruggi y Bichicuí de la Ciudad de La Plata". Becaria de la Universidad Nacional de La Plata. Miembro del proyecto "Las formas de Apropiación y Representación del Patrimonio Antropológico en Museos" (Programa de Incentivos - FCNyM, Universidad Nacional de La Plata). 
Museo de La Plata, Paseo del Bosque S/N (1900), La Plata, Buenos Aires, Argentina, mariacecilialuzdominguez@gmail.com 